\title{
The Changes in Pattern of Myocardial Shortening by Reduction of Regional Coronary Blood Flow
}

\author{
Yoshiro Nakamura, M.D., Junichi Hayashi, M.D., \\ Hidezo Mori, M.D., Satoshi Ogawa, M.D., \\ Fumitaka Ohsuzu, M.D., Masando Takahashi, M.D., \\ Shigehiko Hatrori, M.D., and Muneyuki Horikawa, M.D.
}

\section{Summary}

The relationship between the grade of a decrease in the regional coronary blood flow and the movement of ventricular myocardium of that region was investigated in open chest dog. Blood flow in left anterior descending artery (FLAD) was reduced by stepwise constriction of LAD with ligature. Ventricular segment length was measured in a circumferential plane on the endocardial surface by ultrasonic dimension system. For the elimination of the noise caused by ultrasonic dimension system, the synchronizer was inserted between sample clock of the dimension system and the trigger circuit of the electromagnetic flowmeter.

A $20 \%$ reduction of FLAD affected the pattern of ischemic myocardial shortening very little. Discontinuance of shortening to the end of systole was occurred by a 20 to $60 \%$ reduction in FLAD. Early and/or late systolic bulging was induced by a $60 \%$ reduction of FLAD. Systolic bulging with early diastolic shortening was seen in the cases with a 60 to $80 \%$ reduction in FLAD. Frank systolic bulging which was always seen by complete occlusion of LAD was produced by a 60 to $90 \%$ reduction of FLAD in few cases.

\section{Additional Indexing Words:}

Ultrasonic dimension system Segment length Systolic bulge

Q INCE the classical work of Tennant and Wiggers, ${ }^{1 \prime}$ the changes in pattern $D$ of regional myocardial segment shortening during acute coronary occlusion have been described by several investigators. ${ }^{2)-8}$ However, the precise observations of those changes during a decrease in coronary blood flow were incomplete because of the inappropriate apparatus for continuous measurement of the myocardial segment length. At the present, ultrasonic crystals are considered to be the best equipment as a dimension gauge, ${ }^{91-13}$ but some

From the Department of Internal Medicine, School of Medicine, Keio University and Nihon Kohden Kogyo Co. Ltd.

Address for reprint: Yoshiro Nakamura, M.D., Department of Internal Medicine, School of Medicine, Keio University, Shinanomachi, Shinjuku-ku, Tokyo 160, Japan.

Received for publication June 28, 1979. 
technical expedients were nessesary to apply this technique together with the electromagnetic flowmeter. The purpose of this study is to show the relations between a degree of coronary blood flow reduction and the changes in pattern of myocardial segment shortening in the ischemic area.

\section{Methods}

Fourteen mongrel dogs (15-27 Kg) were anesthetized with sodium pentobarbital $(25 \mathrm{mg} / \mathrm{Kg}$ i.v. $)$. A left thoracotomy was performed via fifth intercostal space under the artificial ventilation by Harverd pump through an endotracheal tube. After the pericardiotomy, the left anterior descending artery (LAD) was dissected about 1 to $3 \mathrm{~cm}$ below the bifurcation and the probe of an electromagnetic flowmeter (EMF, Nihon Koden Kogyo) was applied. Another probe of EMF was placed around the root of ascending aorta. Aortic pressure was measured through a catheter advanced from femoral artery and left ventricular pressure was measured through a short side hole cannula inserted into the apex. A pair of small ultrasonic crystals were implanted into the endocardial surface of the left ventricle perfused by LAD in a circumferential plane. The distance between the crystals was 7 to $15 \mathrm{~mm}$. Continuous measurement of the myocardial segment length was performed by Ultrasonic Dimension System (Schuessler). These hemodynamic measurements were recorded simultaneously on an ink oscillograph.

In this measurement system, the intermoduration which was caused by the interference between electromagnetic flowmeter and ultrasonic dimension system made the recording of blood flow impossible. To avoid this problem, the synchronizer was inserted between the sampling clock of the dimension system and the trigger circuit of the EMF (Fig. 1).

A reduction of blood flow in LAD (FLAD) was produced by inserting the wedge into the loop of the ligature tied loosely around LAD distal to EMF probe (Fig. 2). With this technique, precise adjustment of FLAD was impossible and continuous hemodynamic changes produced by stcpwise rcduction of FL $\Lambda \mathrm{D}$ could not be recorded in each case.

After recording hemodynamic data of the control state, hemodynamic changes were observed during LAD obstruction of $15 \mathrm{sec}$ and after release of it. When all

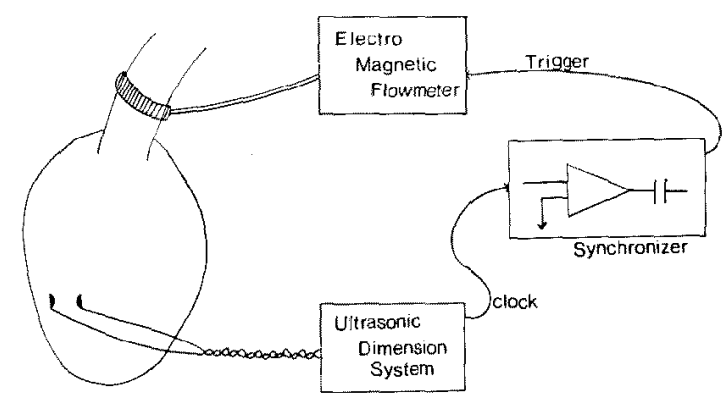

Fig. 1. To avoid intermoduration the synchronizer was inserted between the sampling clock of the dimension system and the trigger circuit of the electromagnetic flowmeter. 


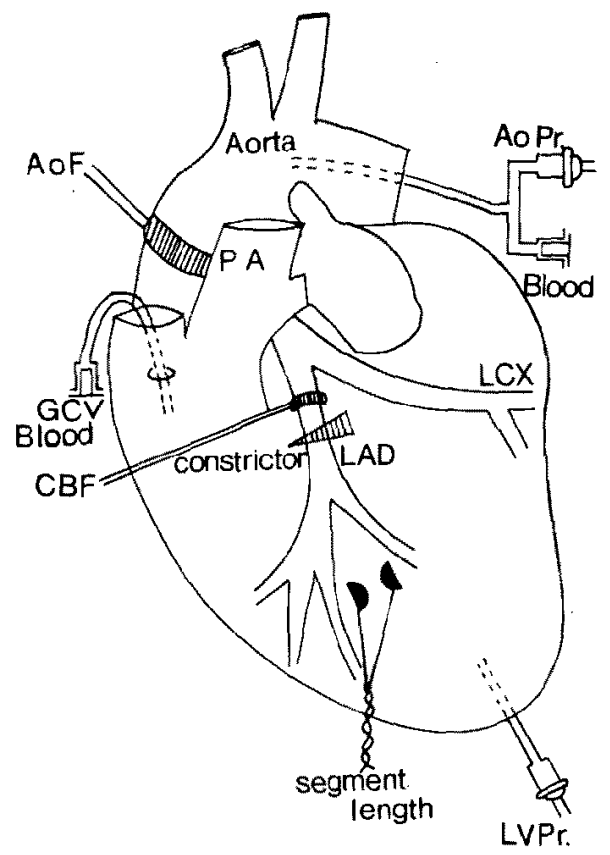

Fig, 2. Schematic diagram of preparation. AoPr=aortic pressure; $\mathrm{AoF}=$ aortic blood flow; $\mathrm{CBF}=$ coronary blood flow; $\mathrm{LAD}=$ left anterior descending artery; $L V P r=$ left ventricular pressure; $L C X=$ left circumflex artery; $\mathrm{PA}=$ pulmonary artery; $\mathrm{GCV}=$ great cardiac vein.

hemodynamic data returned to the control state, FLAD was reduced to as many stages as possible. To get steady state, stable FLAD was kept for $5 \mathrm{~min}$.

\section{Resultt}

Course of the formation of the systolic bulge in the left ventricle by $L A D$ occlusion:

During 5 min of LAD occlusion in 5 cases, the course of systolic bulge formation was observed. Four characteristic patterns were found in each experiment (Fig. 3). Discontinuance of shortening of the myocardial segment to the end of systole or late systolic elongation occurred as the first change (Stage 1). Following this stage, early and late systolic bulging accompanied with or without early diastolic shortening was appeared (Stage 2). The stage of systolic bulging with early diastolic shortening (Stage 3) was likely to be followed by the stage of more prominent pansystolic bulge and disappearance of early diastolic shortening (Stage 4). Although progressive elongation of the myocardial segment at the end of diastole made the determination of that pattern sometimes difficult, the shift from one stage to another was consistently appreciated but continuation of each stage was variable. 


\section{PATTERN}

\section{OF SEGMENT LENGTH}

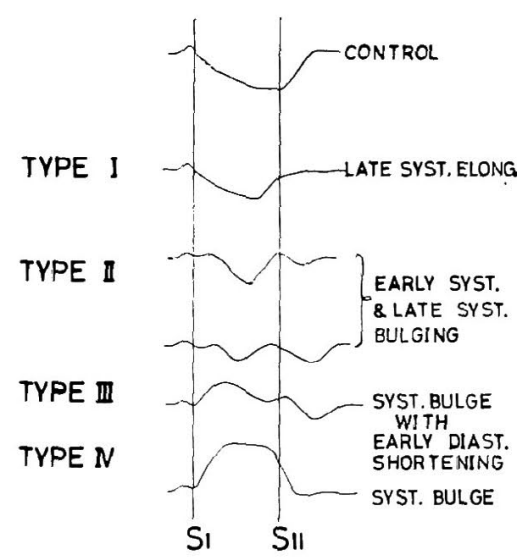

Fig. 3. Four characteristic patterns of segment length in the ischemic area after the ligation of the left anterior descending artery.
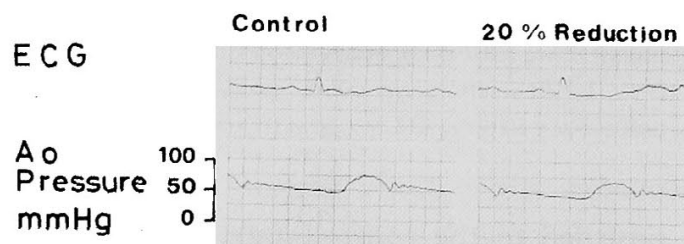

Ao

Flow 1 o

$1 / \mathrm{min}$

$\left.\begin{array}{lr}\text { LV } & 100 \\ \text { Pressure } & 50 \\ \text { mmHg } & 0\end{array}\right]$

Co Phasic

Flow r $\left.\begin{array}{cc}50 \\ \text { Clow }\end{array}\right]$

$\mathrm{ml} / \mathrm{min}$

Co Mean

$\left.\begin{array}{lr}\text { Flow } & 50 \\ \mathrm{ml} / \mathrm{min} & 0\end{array}\right]$

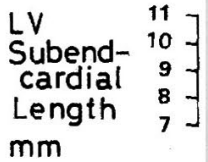

Fig. 4. The representative recordings of hemodynamics following a $20 \%$ reduction of left anterior descending coronary blood flow. Ao=aorta; LV $=$ left ventricle; $\mathrm{CO}=$ coronary. 
The course of the disappearance of bulge during reperfusion was roughly in a retrograde fashion of the course of bulge formation, but close observation disclosed many exceptional changes in pattern.

Relation between a decrease in coronary blood flow and the changes in pattern of myocardial segment shortening:

Twenty-one tracings in 6 stages of reduction in FLAD, namely $20 \%$, $40 \%, 60 \%, 80 \%, 90 \%$, and $100 \%$ reduction, were obtained. Three of cases with a $20 \%$ reduction did not reveal any change in pattern of myocardial segment shortening in the ischemic area (Fig. 4). One case with a $20 \%$ reduction showed the stage 1 pattern. A $40 \%$ reduction of FLAD which was produced only in 1 case, resulted in the stage 1 pattern of ischemic myocardial segment shortening (Fig. 5). The changes in pattern of myocardial segment shortening induced by a $60 \%$ reduction of FLAD were extremely variable. Fig. 6 showed an example of early systolic hypokinesis and endsystolic small

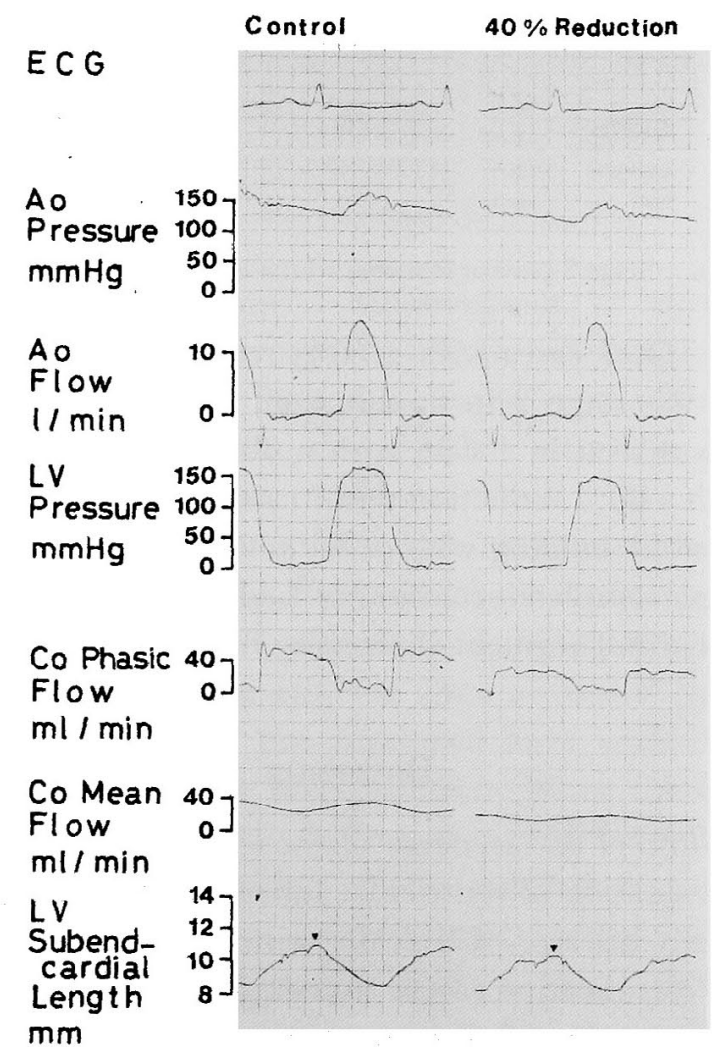

Fig. 5. Stage 1 pattern in a case with a $40 \%$ reduction in FLAD. FLAD $=$ blood flow in LAD. 


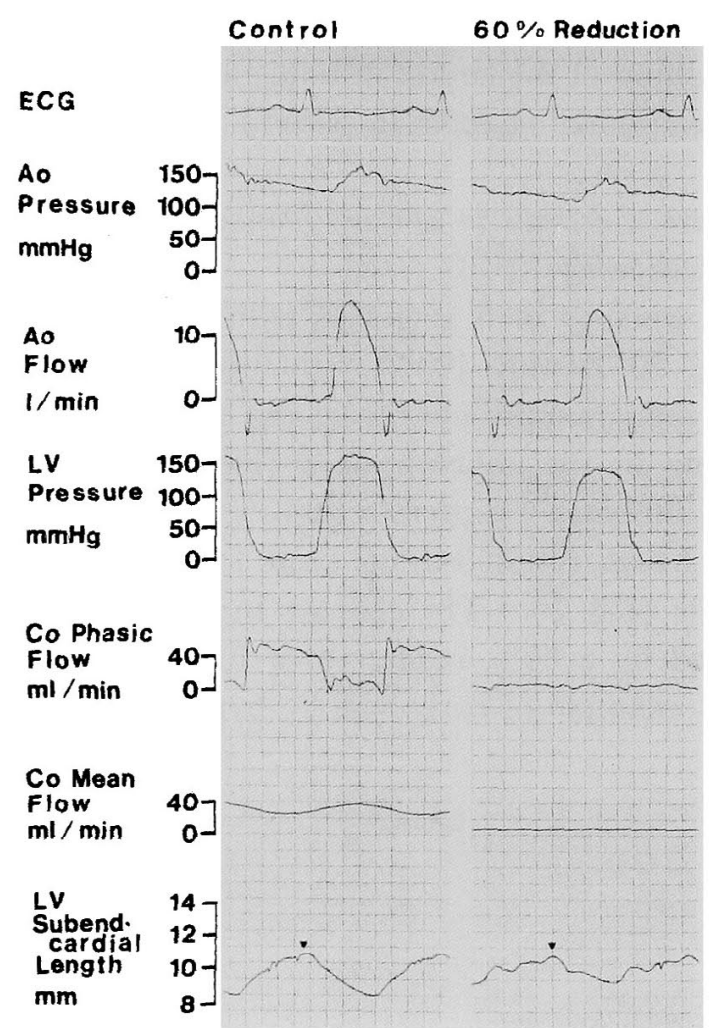

Fig. 6. Stage 2 pattern in a case with a $60 \%$ reduction in FLAD.

bulge (Stage 2). Of 7 cases with a $60 \%$ reduction, the stage 1 pattern was introduced in 2, the stage 2 in 3 , the stage 3 in 1 , and stage 4 in 1 . The stage 3 pattern was seen in 1 case with a $80 \%$ reduction of FLAD (Fig. 7). Other 2 cases with a $80 \%$ reduction and 1 case with a $90 \%$ reduction of FLAD revealed frank systolic bulging with or without early diastolic shortening (Fig. 8). In all 5 cases, complete occlusion of LAD for 5 min introduced the stage 4 pattern of myocardial segment shortening in the ischemic area (Table I).

\section{DisGussion}

The recognition of the asynergy of the left ventricle has become very important for the evaluation of ventricular function and prognosis in the patients with ischemic heart disease. Clinically, cineventriculography is widely used according to the classification of the asynergic movement of the left ventricle by Herman et al. ${ }^{14)}$ For the documentation of the relative or reversible ischemic zone, stress cineventriculography has been examined. ${ }^{15)}$ Our study was directed to be a basis of the analysis of cineventriculography from the 


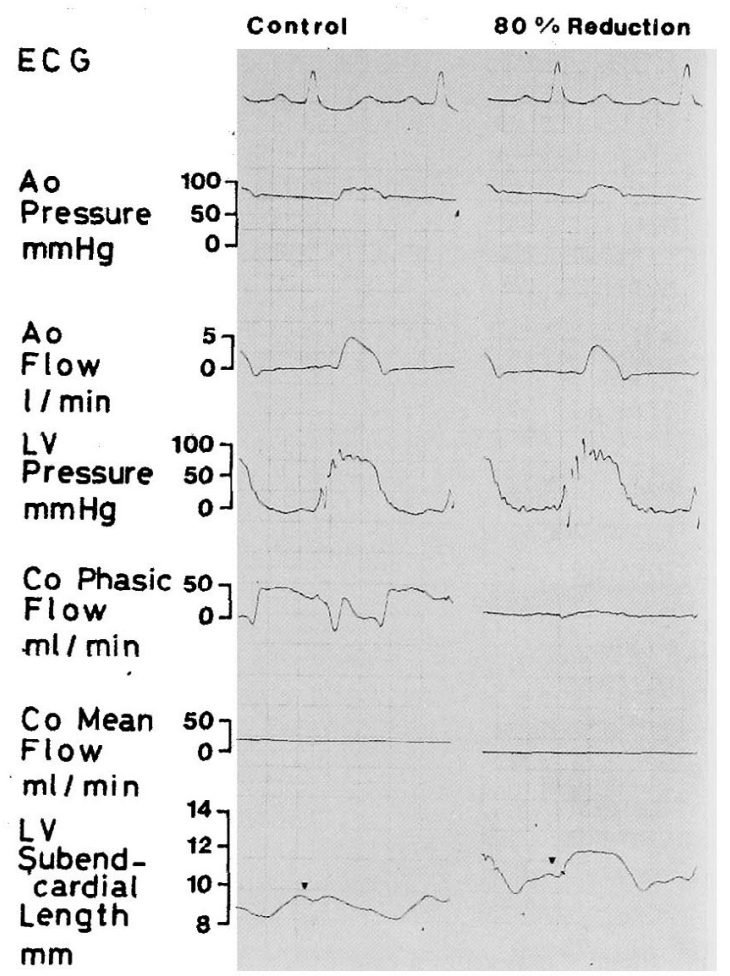

Fig. 7. Stage 3 pattern in a case with a $80 \%$ reduction in FLAD.

mechano-biochemical standpoint. Measurement of myocardial segment length had been done by the mercurly-in-Silastic tubing segment length gauge or very soft strain gauge arch. Both of the transducers were not enough compliant, not to distort the diastolic shape of left ventricle. In this meaning, ultrasonic crystals can be the best transducer.

Regional myocardial function has been widely studied by means of a Walton-Brodie strain gauge arch, ${ }^{16)-19)}$ which measures isometric developed tension. What was measured by this method, however, was very confusing. As Lewantowski et $\mathrm{al}^{201}$ pointed out, the force measured by the strain gauge arch was a difference between the developed force under the arch and the force developed by surrounding myocardium. When the change in preload affected ventricular diameter, this difference would not reflect the change in the developed force under the arch. We have shown that the force measured by this method could represent myocardial contractility when left atrial pressure was kept constant. ${ }^{20)}$ Therefore, Yoshida's study ${ }^{21)}$ in which the changes in contraction force of ischemic left ventricle was measured by this method during coronary obstruction would be incorrect, although left ventricular enddiastolic pressure was not changed markedly. 


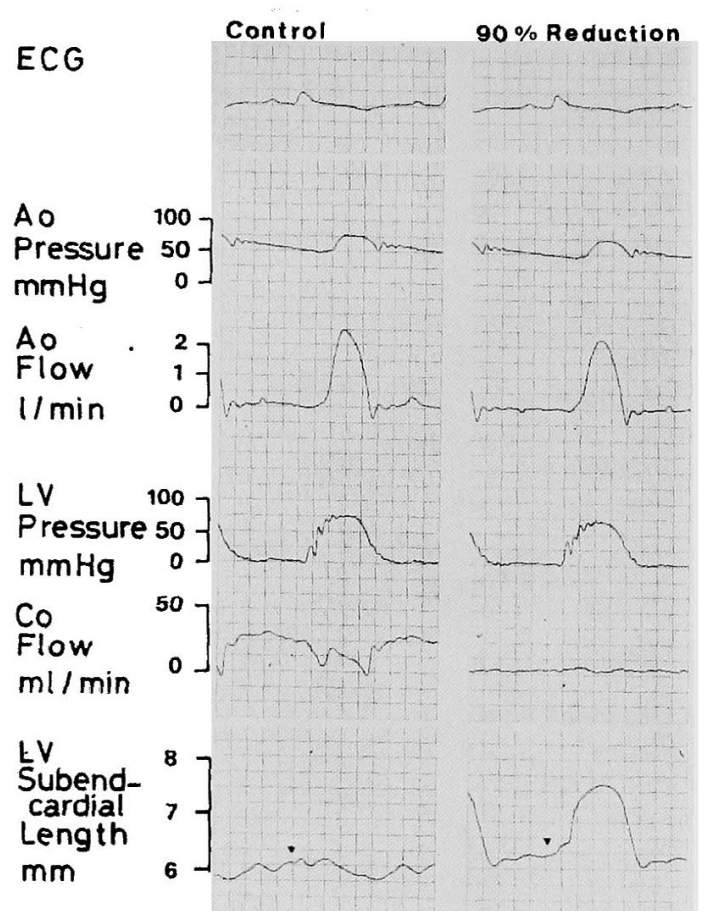

Fig. 8. Stage 4 pattern in a case with a $90 \%$ reduction in FLAD.

Table I. The Relationship between Percent Reduction in Coronary Blood Flow and Pattern of Segment Length

\begin{tabular}{|c|c|c|c|c|c|c|c|}
\hline \multirow{2}{*}{$\begin{array}{l}\text { Pattern of } \\
\text { Segment Length }\end{array}$} & \multicolumn{7}{|c|}{ Percent Reduction in Coronary Flow } \\
\hline & $0 \%$ & $20 \%$ & $40 \%$ & $60 \%$ & $80 \%$ & $90 \%$ & $100 \%$ \\
\hline Type 0 & 14 & 3 & & & & & \\
\hline I & & 1 & 1 & 2 & & & \\
\hline II & & & & 3 & & & \\
\hline III & & & & 1 & 1 & & \\
\hline IV & & & & 1 & 2 & 1 & 5 \\
\hline Total & 14 & 4 & 1 & 7 & 3 & 1 & 5 \\
\hline
\end{tabular}

In this respect, direct measurement of myocardial segment length using an ultrasonic dimension gauge appears an ideal approach to the evaluation of regional myocardial function.

Concerning the course of bulge formation, our data was very similar not only to the data presented by Theroux et al, ${ }^{22)}$ but also to other data which were obtained by technically incomplete method to measure segment length. It was very interesting that the duration of ischemia had a similar effect of 
grade of reduction of coronary flow upon myocardial segment shortening. The explanation of this similarity was remained in further investigation.

\section{REFERENCES}

1. Tennant $\mathrm{R}$, Wiggers $\mathrm{CJ}$ : The effect of coronary occlusion on myocardial contraction. Am J Physiol 112: 351, 1935

2. Prinzmetal M, Schwartz LL, Corday E, Spritzler R, Bergman HC, Kruger HE: Studies on the coronary circulation. VI Loss of myocardial contractility after coronary artery occlusion. Ann Int Med 31: 429, 1949

3. Tyberg JV, Forrester JS, Whatt HL, Goldner SJ, Parmley WW, Swan HJC: An analysis of segmental ischemic dysfunction utilizing the pressure-length loop. Circulation 49: 748, 1974

4. Forrester JS, Tyberg JV, Whatt HL, Goldner SJ, Parmley WW, Swan HJC: Pressure-length loop. A new method for simultaneous measurement of segmental and total cardiac function. J Appl Physiol 37: 771, 1974

5. Forrester JS, Whatt HL, da Luz PL, Tyberg JV, Diamond GA, Swan HJC: Functional significance of regional ischemic contraction abnormalities. Circulation 54: 64, 1976

6. Pirzada FA, Ekong FA, Vokonas PS, Apstein CS, Hood WB: Experimental myocardial infarction XIII. Sequential changes in left ventricular pressure-length relationships in the acute phase, Circulation 53: 970, 1976

7. Nakamura Y, Nagoshi II, Takei F, Matsumura N, Hattori S, Sasamoto H: The inhomogenous movement of the left venctricle induced by coronary artery occlusion. Jap Heart J 13: 150,1972

8. Nakamura Y, Handa S: Right ventricular function. Jap Circulat J 38: 861, 1974

9. Franklin D, Kemper WS, Patrick T, Mckown D: Technique for measurement of regional myocardial segment dimensions in chronic animals. Fed Proc 32: 343, 1973

10. Sasayama S, Franklin D, Ross J Jr, Kemper WS, McKown D: Dynamic changes in left ventricular wall thickness and their use in analyzing cardiac function in the conscious dog. Am J Cardiol 38: 870, 1976

11. Theroux P, Ross J Jr, Franklin WS, Kemper WS, Sasayama S: Regional myocardial function in the conscious dog during acute coronary occulusion and responses to morphine, propranolol, nitroglyccrin and lidocainc. Circulation 53: 302, 1976

12. Sasayama S, Osakada G, Takahashi M, Hamashima H, Hirose K, Nishimura E, Kawai C: Effects of intraaortic balloon counterpulsation on regional myocardial function during acute coronary occlusion in the dog. Am J Cardiol 43: 59, 1979

13. Lekven J, Mjos OD, Kjekshus JK: Compensatory mechanisms during graded myocardial ischemia. Am J Cardiol 31: 467, 1973

14. Herman MV, Heinle RA, Klein MD, Gorlin R: Localized disorders in myocardial contraction. Asynergy and its role in congestive heart failure. New Engl J Med 277: 222, 1967

15. Flessas AD, Connelly GD, Handa S, Tilney CR, Kloster CK, Rimmer RH Jr, Keefe JF, Klein MD, Ryan TJ: Effect of isometric exercise on the enddiastolic pressure, volumes, and function of the left ventride in man. Circulation 53: 839, 1976

16. Walton PR, Brodie OJ: The effect of drugs on the contractile force of a section of the right ventricle under condition of an intact circulation. J Pharmacol Exp Therap 90:26, 1947

17. Hisada S: Myocardial contractility and pumping function of the ventricle. Jap Circulat $J$ 33: 789,1968

18. Schelbert HR, Covell JW, Burns JW, Maroko PR, Ross J Jr.: Observations on factors affecting local forces in the left ventricular wall during acute myocardial ischemia. Circulat $\operatorname{Res} 29: 306,1971$ 
19. Banka VS, Bodenheimer MM, Helfant RH: Nitroglycerin in experimental myocardial infarction. Effects on regional left ventricular length and tension. Am J Cardiol 36: 453, 1975

20. Nakamura Y, Takahashi M, Hattori S: Behavior of asynergic ventricle. Jap Heart J 18: 729,1977

21. Yoshida S: Experimental studies of coronary insufficiency 1. Changes in myocardial contractility in the ischemic area of the ventricle following acute coronary occlusion. Jap Circulat J 33: 1253, 1969

22. Theroux P, Franklin D, Ross J Jr, Kemper WS: Regional myocardial function during acute coronary artery occlusion and its modification by pharmacologic agents in the dog. Circulat Res 35: 896, 1974 